\title{
ANNIE ERNAUX, UMA ESCRITORA TRÂNSFUGA DE CLASSE
}

- ISADORA DE ARAÚJO PONTES

\section{RESUMO}

Este trabalho é resultado de uma leitura crítica da obra referencial de Annie Ernaux, centrada, sobretudo, em L'événement (2000) narrativa sobre seu aborto clandestino. Nosso objetivo consistiu em analisar como a mobilidade entre as classes sociais vivida pela autora, que pode ser considerada uma "trânsfuga de classe", se manifesta em sua escrita, produzindo uma obra que conjuga questões sociais e de gênero (gender), buscando operar, através da literatura, um encontro da memória pessoal e coletiva.

Palavras-chave: Annie Ernaux, Pierre Bourdieu, aborto, classe social, trânsfuga de classe

\section{ABSTRACT}

This paper is the result of a critical reading of Annie Ernaux's referential work, centered mainly on L'événement (2000), narrative about her clandestine abortion. Our objective was to analyze how the mobility between social classes lived by the author, who can be considered as a "class defector", express itself in her writing, producing a work that combines social and gender issues, seeking to operate, through literature, an encounter of personal and collective memory.

Keywords: Annie Ernaux, Pierre Bourdie, abortion, social class, class defector 
A pesar de ter assumido, a partir de La place [O lugar] $(1983)^{1}$, a forma da autobiografia, a abordagem do "eu" de Annie Ernaux é feita à distância. $O$ lugar de enunciação em suas narrativas não parece ser o da experiência de um indivíduo único à parte do mundo, mas o de um "eu" transpessoal, como podemos observar na afirmação da autora, no prefácio de Écrire la vie:"Sempre escrevi ao mesmo tempo sobre mim e fora de mim, o "eu" que circula de livro em livro não é assinalável a uma identidade fixa e sua voz é atravessada por outras vozes, parentais e sociais, que nos habitam" (p. 7) ${ }^{2}$. Sua condição de trânsfuga indivíduo que abandona a classe social de origem e ascende à classe dominante - parece ser um dos fatores que engendram esse distanciamento, pois, apesar de ser uma intelectual, essa posição foi conquistada através de um processo de deslocamento social, e não como um direito de sua classe de origem, distante, social e geograficamente, do mundo burguês intelectualizado.

Essa distância de si a partir da qual escreve permite a presença da alteridade em sua obra, que ultrapassa o "eu", sendo, muitas vezes, uma escrita do "nós" e do outro. Segundo Violaine Houdart-Merot (2015), esse caráter de sua escrita possibilita à autora romper com o pudor e o não dito e abordar temas considerados vergonhosos. Ernaux busca a escrita referencial a partir de La place, obra em que narra a relação com o pai e seu sentimento de traição filial e social:

Para dar conta de uma vida submetida à necessidade, não tenho o direito de tomar primeiro o partido da arte, nem de buscar fazer algo "apaixonante" ou "emocionante". Reunirei as palavras, os gestos, os gostos de meu pai, os fatos marcantes de sua vida, todos os signos objetivos de uma existência que também compartilhei. Nenhuma poesia de lembrança ou ironia jubilante. A escrita plana me vem naturalmente, aquela mesma que eu utilizava outrora escrevendo a meus pais para contar-Ihes as novidades essenciais. (p. 442$)^{3}$

A partir dessas considerações, a hipótese a ser explorada neste trabalho é verificar como se articulam a relação e a identificação da autora com o outro e com seu meio de origem, a partir da associação do lugar físico, o lugar onde foi vivida a experiência, ao lugar social - a classe dominada de origem da autoranarradora - na narrativa de seu aborto realizado clandestinamente em janeiro de 1964, publicado em uma autobiografia, L'événement, apenas em 2000. As experiências presentes nas obras de Ernaux se passam, frequentemente, em uma localidade que a autora afirma revisitar durante a escrita ou uma vez finda a narrativa. Como é o caso da "passagem Cardinet", lugar onde habita a mulher que realiza o procedimento de interrupção da gravidez, em L'événement ${ }^{4}$. Assim, analisaremos como as questões relacionadas à classe social são mobilizadas
[1] ERNAUX, Annie. La place. In : Écrire la vie. Paris Quatro-Gallimard, 2011, p. 442.

[2] “J'ai toujours écrit à la fois de moi et hors moi, le « je » qui circule de livre en livre n'est pas assignable à une identité fixe et sa voix est traversée par les autres voix, parentales, sociales, qui nous habitent."(ERNAUX, Annie. Écrire la vie. Paris : Quatro-Gallimard 2011, p. 7).

[3] "Pour rendre compte d'une vie soumise à la nécessité, je n'ai pas le droit de prendre d'abord le parti del'art, ni de chercher à faire quelque chose de "passionant", ou d'émouvant". Je rassemblerai les paroles, les gestes, les goûts de mon père, les faits marquants de sa vie, tous les signes objectifs d'une existence que j'ai aussi partagée." (ERNAUX, 2011, p. 442, tradução nossa assim como todas as traduções citadas neste artigo).

[4] ERNAUX, Annie. L'événement. In : Écrire la vie. Paris Quatro-Gallimard, 2011, p. 270-321. 
[5] "un choc ontologique violent" (ERNAUX, Bourdieu: Le chagrin. Le Monde, 05/02/2002. Disponivel em: http://www.homme-moderne.org/societe/socio/ bourdieu/mort/aernau.html).

[6] 'Et, pour peu qu'on soit issu soi-même des couches sociales dominées, I'accord intellectuel qu'on donne aux analyses rigoureuses de Bourdieu se double du sentiment de l'évidence vécue, de la véracité de la théorie en quelque sorte garantie par l'expérience: on ne peut, par exemple, refuser la réalité de la violence symbolique lorsque, soi et ses proches, on I'a subie." (ERNAUX, 2002).

[7] "la réalité objective des rapports sociaux" (ERNAUX, 2002). na obra, o lugar de passagem ocupado pela autora-narradora e sua relação com sua posição de mulher de origem dominada. Para que isto seja possível, primeiramente, levantaremos alguns conceitos de Pierre Bourdieu e sua interação com os textos de Ernaux. Após esse momento, analisaremos a forma como o lugar "passagem Cardinet" aparece na obra, procurando relacionar a presença das diferentes localidades nos textos de Ernaux a seu lugar social, à própria noção de passagem e à sua posição de trânsfuga de classe. Por fim, analisaremos como o aborto sofrido pela autora-narradora conjuga as violências de classe e de gênero.

\section{ANNIE ERNAUX E PIERRE BOURDIEU}

A própria autora evidencia a contribuição do sociólogo Pierre Bourdieu para os temas que evoca em sua escrita, a exemplo do artigo que escreve por ocasião de sua morte, "Le chagrin", em 2002. Nesse artigo, Ernaux discorre sobre como a obra de Bourdieu foi recebida por ela: "um choque ontológico violento" (ERNAUX, 2002) $)^{5}$ que lhe permitiu compreender as estruturas de dominação social, que fazem parte da sua própria história:

E, quando se é oriundo das camadas sociais dominadas, a concordância intelectual que se dá às análises rigorosas de Bourdieu se associa ao sentimento de evidência vivida, da veracidade da teoria de alguma forma garantida pela experiência: não se pode, por exemplo, recusar a realidade da violência simbólica quando você e seus próximos a sofreram. ${ }^{6}$

Ernaux utiliza as categorias de Bourdieu para se referir às classes como dominadas e dominantes ao invés de termos como "meio modesto" ou "camadas superiores", utilizados na linguagem comum para se referir à distinção de classe. Como explica, no artigo, para ela, essas denominações mudam radicalmente a forma pela qual as separações sociais são vistas, pois rompem com o eufemismo que passa uma ilusão de naturalidade e denunciam "a realidade objetiva das relações sociais" ${ }^{7}$

A obra do sociólogo francês compreende uma teoria das estruturas sociais, partindo de conceitos-chave, e voltando-se para a análise dos mecanismos de dominação social. Segundo ele, o indivíduo e o meio social não estão em lados opostos, mas ambos são constituídos de formas de viver, pensar e se comportar que lhe foram atribuídas, sem que haja consciência, por suas condições materiais. Tais formas constituem os condicionamentos de uma classe, o habitus. Presente desde o princípio da percepção de toda experiência, como um passado que sobrevive, o habitus funciona como uma materialização da memória coletiva, sendo um dos elementos da reprodução das relações de dominação. Ele pode 
ser pensado como o modus operandi traduzido no opus operatum de um conjunto de indivíduos que compartilham do mesmo sistema de disposições, formando uma classe social. Dessa forma, essas disposições tendem a engendrar certas condutas ajustadas à lógica característica de um determinado campo social e, portanto, razoáveis por terem sido internalizadas ao ponto de serem compreendidas como naturais. Nessa operação, ele produz, igualmente, efeitos que se inscrevem no próprio corpo e crença do indivíduo, funcionando como marcas de distinções:

Os estilos de vida são, assim, os produtos sistemáticos dos habitus que, percebidos em suas relações mútuas segundo esquemas do habitus, tornam-se sistemas de sinais socialmente qualificados — como "distintos", "vulgares", etc. A dialética das condições e dos habitus é o fundamento da alquimia que transforma a distribuição do capital, balanço de uma relação de forças, em sistema de diferenças percebidas, de propriedades distintivas, ou seja, em distribuição de capital simbólico, capital legítimo, irreconhecível em sua verdade objetiva. ( p. 164) ${ }^{8}$

Destarte, os habitus compreendem as formas de perceber o mundo, agir, julgar, se comportar, falar, se vestir, se alimentar etc., podendo ser reconhecidos como distintos, quando esses sistemas atestam um conjunto de capitais legitimados, ou, se não há essa legitimidade, vulgares. Relacionadas a essa noção, temos as diferentes formas de capitais teorizadas por Bourdieu, cujo acúmulo funciona como signos de distinção ou vulgaridade, determinando a diferenciação entre as classes. Faz-se mais significativa, para nós, a noção de capital cultural, que representa o saber e o conhecimento, garantido por certificados, títulos ou diplomas.

Annie Ernaux destaca em suas obras e artigos o papel da escola - tema central para Bourdieu — no processo de aquisição do capital necessário para um olhar distanciado em relação às produções culturais. Bourdieu ${ }^{9}$ rompe com a concepção da escola enquanto instituição que busca nivelar, minimizando as diferenças sociais. Sendo assim, a cultura representa também uma forma de poder e o sistema escolar contribui para a reprodução das estruturas das relações de classe, ao reforçar as distinções e privilegiar aqueles indivíduos que possuem o capital cultural incorporado. A capacidade para a apreciação estética, por exemplo, distanciada do prazer imediato ou de uma associação direta com a vida varia de acordo com a origem social, que age diretamente na relação com a cultura na realidade, pois os domínios considerados mais legítimos são apreendidos a partir da herança do meio de origem.

Considerando-se que Annie Ernaux nasceu num meio dominado social
[8] PIERRE, Bourdieu. A Distinção. Porto Alegre: Zouk, 2011.

[9] PIERRE, Bourdieu, PASSERON, Jean-Claude. A reprodução: elementos para uma teoria do sistema de ensino. Petrópolis: Vozes, 2008. 
[10] "Ultérieurement, la sociologie me fournira le terme adéquat pour cette situation précise, celui de "transfuge de classe" ou encore de “déclassée par le haut”. L'année même où j'ai perdu mon père, j'ai été nommée, pour mon premier poste de professeur, dans um lycée avec des classes techniques, et il s'est opéré pour moi un retour au réel. En face de moi, quarante élèves dont la marjorité était issue de la classe paysanne et ouvrière de Haute-Savoie. Je mesurais le décalage profond entre leur culture d'origine et la littérature que je leur enseignais. Je constatais aussi l'injustice d'une reproduction des inégalités sociales au travers l'école." (ERNAUX, Annie. Retour à Yvetot. Paris : Editions du Mauconduit, 2013, p. 29).

[11] BOURDIEU, PASSERON, 2008.

[12] Certificado de Aptidão ao Professorado do Ensino Secundário. Trata-se de um certificado obrigatório para toda pessoa que deseja lecionar nos quatro últimos anos do Ensino Fundamental e no Ensino Médio. e intelectualmente e ascendeu à classe dominante, através do processo de aculturação, ela pode ser considerada, para a sociologia, uma "trânsfuga de classe" que não teve desde o berço a legitimação de uma herança cultural. É exigido do trânsfuga uma mudança total de seus valores e uma conversão de sua atitude, abandonando seu habitus de origem para incorporar aquele da classe dominante. A autora se apropria dessa denominação, bem como de outros conceitos do sociólogo, como no trecho a seguir:

Ulteriormente, a sociologia me fornecerá o termo adequado para essa situação precisa, o de "trânsfuga de classe" ou ainda de "desclassificada por ascensão". No mesmo ano em que perdi meu pai, fui nomeada para meu primeiro cargo de professora, em um colégio técnico, e se operou para mim um retorno ao real. Na minha frente, quarenta alunos cuja maioria era oriunda da classe camponesa e operária da região da Haute-Savoie. Media a distância profunda entre a cultura de origem deles e a literatura que Ihes ensinava. Constatava também a injustiça de uma reprodução de desigualdades sociais através da escola. (p. 29, grifo nosso) $)^{10}$

Ernaux evoca o momento em que percebeu a distância de sua classe de origem, reconhecendo sua mobilidade social pelo acúmulo de capital cultural. Tal forma de capital possui um lado incorporado a partir da socialização primária, ou seja, herdado da família, e um lado institucionalizado, que parte do reconhecimento legal, através de títulos e diplomas, de sua aquisição. Ele indica o acesso a uma cultura considerada como mais legítima que as outras, de acordo com o movimento do grupo dominante em prol desse reconhecimento. Segundo Bourdieu e Passeron a ação pedagógica impõe um arbitrário cultural, que consiste na reprodução da cultura dominante "contribuindo, desse modo para reproduzir as estruturas das relações de força, numa formação social onde o sistema de ensino dominante tende a assegurar-se do monopólio da violência simbólica legítima" (p. 27) .11

Ainda que o sistema escolar não contribua abertamente, o processo de aculturação pode funcionar como um veículo de mobilidade de classe, contribuindo para que um indivíduo alcance uma determinada posição social. Tal processo se dá pela assimilação do sistema de valores da classe privilegiada e da cultura por ela considerada legítima. No caso de Annie Ernaux, ele foi garantido pela obtenção de um diploma universitário em Letras e pela aprovação no C.A.P.E.S. ${ }^{12}$. Em La place, a autora aborda o distanciamento do pai, associando-o a sua ascensão à classe dominante, o que a colocaria em um lugar de "traidora" de sua classe de origem, como propõe Jovita Maria Gerheim Noronha: 
O termo usado pela autora, trânsfuga, que remete à ideia de deserção - em sua primeira acepção, soldado ou militar que, em tempo de guerra, deserta das fileiras do exército de seu país e passa a servir no exército inimigo - e de dissidência, define bem a problemática que atravessa todas as suas obras, mas que é explorada de maneira privilegiada nas narrativas parentais, sobretudo em La place: a de alguém que traiu a própria classe a dos pais - e passou para o lado adverso. (p. 174) ${ }^{13}$

A condição de "trânsfuga" da autora pode dessa forma ser relacionada a um sentimento de traição de sua origem social que passa pelo próprio ato de escrever, uma vez que o campo da literatura demanda, igualmente, certo capital cultural, como podemos observar nas reflexões que Ernaux faz sobre sua escrita em Retour à Yvetot:

Será que sem me questionar, vou escrever na língua literária na qual entrei por efração, "a língua do inimigo" como dizia Jean Genet, entendam por isso o inimigo de minha classe social? Como posso eu, de certa forma imigrada do interior, escrever? Desde o início, estive presa em uma tensão, em uma laceração, entre a língua literária, aquela que estudei, amei, e a língua de origem, a língua da casa, de meus pais, a língua dos dominados, aquela da qual tive vergonha em seguida, mas que sempre ficará em mim. No fundo, a pergunta é: Como, ao escrever, não trair o mundo do qual vim? (pp. 31-32, grifo da autora) ${ }^{14}$

Seu sentimento de traição parece ser inerente a seu lugar de trânsfuga, de modo que a questão sobre em qual língua escrever pode ser compreendida como a sensação de não ter uma língua própria, pois a língua da literatura é a do mundo intelectual e burguês oposta àquela de sua origem social, que pertence ao mundo por ela "desertado". O processo de ascensão social do indivíduo se dá de forma gradual, como podemos observar nas narrativas em que a autora expressa como se deu esse movimento que leva à rejeição dos costumes do seu meio de origem. Devido à educação, ela passou, então, a integrar a classe dominante. Entretanto, a condição de trânsfuga também pode ser compreendida como um lugar entre os mundos sociais, posto que as regras desse novo jogo não são vividas com a mesma naturalidade daqueles que ali nasceram. A condição de trânsfuga de classe representa uma posição ainda diferente daquele que nasce entre os dominantes, assim como o falante de uma língua estrangeira não está na mesma posição dos falantes nativos. Sendo assim, a autora se mantém nesse lugar de passagem entre duas classes, por ser traidora da classe de origem, a
[13] NORONHA, Jovita Maria Gerheim. "Interfaces entre biografia e autobiografia na obra de Annie Ernaux". São João Del Rei: UFSJ, 2014.

[14] "Est-ce que, sans me poser de questions, je vais écrire dans la langue littéraire où je suis entrée par effraction. "la langue de l'ennemi" comme disait Jean Genet, entendez l'ennemi de ma classe sociale? Comment puis-je écrire, moi, en quelque sorte immigrée de l'intérieur? Depuis le début, j'ai été prise dans une tension, un déchirement même, entre la langue littéraire, celle que et j'ai étudiée, aimée, et la langue d'origine, la langue de la maison, de mes parents, la langue des dominés, celle dont j'ai eu honte ensuite, mais qui restera toujours en moimême. Tout au fond, la question est: comment, en écrivant, ne pas trahir le monde dont je suis issue?" (ERNAUX, 2013, pp. 31-32). 
[15] Paris é uma cidade composta por vinte regiões divididas sob o nome de "arrondissement".
[16] ERNAUX, Annie. Les armoires vides. In : Écrire la vie. Paris Quatro-Gallimard, 2011, pp. 103-209.

[17] "serait le lieu étroit de l'angoisse sociale, d'une fatalité qui trouve son expression aussi bien dans la doxa populaire (histoires de traînées) que dans la littérature réaliste-naturaliste" (THUMEREL, Fabrice. Passage(s) Ernaux. Paris : Presses Sorbone Nouvelle, 2015).

[18] "Sur la plaque de la rue, il était indiqué 'passage Cardinet', et non 'impasse Cardinet', c'était un signe qui me soulageait." (ERNAUX, 2011, p. 298). qual desertou, e por ter entrado ilicitamente na outra classe - como sugere o termo "por efração", que remete a um roubo por arrombamento - inimiga de sua classe de origem.

\section{PASSAGEM CARDINET E OUTRAS PASSAGENS}

A experiência do aborto aparece na narrativa de L'événement fortemente relacionada à noção de passagem, representada fisicamente pela passagem Cardinet - endereço do lugar ao qual retorna mesmo após a experiência do procedimento abortivo, que ocorre através da introdução da sonda -, e socialmente pela ascensão da autora à classe dominante. Nosso objetivo nessa seção consiste em abordar como se apresenta a conexão com esse lugar material, que é mencionado em outros textos da autora, procurando observar como os diferentes lugares figuram em suas obras e interagem com sua posição de trânsfuga.

$\mathrm{Na}$ obra em questão, quando a autora-narradora busca uma forma de abortar, ela toma conhecimento de uma estudante, designada pelas iniciais de L.B., que realizara um aborto que quase a levou à morte. Após ser contatada pela moça, consegue o endereço da mulher que operava os procedimentos: a passagem Cardinet no XVIle arrondissement ${ }^{15}$ em Paris. O endereço, porém, é apresentado à autora-narradora, a princípio, como "impasse Cardinet", em francês, beco sem saída na acepção própria do termo. O português herdou o termo apenas em sua acepção figurada como indica o dicionário Houaiss quanto à etimologia da palavra: fr. impasse (1761) "rua sem saída", p.ext. "situação sem saída, dificuldade sem solução". Como destaca Fabrice Thumerel — em estudo sociogenético que visa estabelecer a relação entre o espaço e o tempo social na obra de Ernaux, a partir de obras que narram sua passagem social, tais quais L'événemente Les armoires vides [Armários vazios] (1974) ${ }^{16}$ — o impasse"seria o lugar estreito da angústia social, de uma fatalidade que encontra sua expressão tanto na doxa popular (histórias de vagabundas) quanto na literatura realistanaturalista" (p.112)17. A dupla acepção da palavra impasse em francês evoca uma ausência de solução que pode ser associada à própria situação da autoranarradora. O nome equivocado, "impasse", quando lido metaforicamente sugere a ameaça da impossibilidade de se fugir ao destino da maternidade, da suposta desonra da mãe solteira, e de sua classe social, diferentemente do termo passage que vai tranquilizá-la: "Na placa da rua, estava indicado "passage Cardinet", e não "impasse Cardinet", foi um sinal que me confortou" (p. 298) ${ }^{18}$. Em francês o termo passage designa uma rua pequena só para pedestres, muitas vezes coberta (como as galerias) que une duas artérias. Assim, a mudança na designação do logradouro parece sugerir metaforicamente a possibilidade de resolução de uma situação aparentemente sem saída. 
Embora a passagem Cardinet seja descrita pela autora como o lugar do aborto, a expulsão do feto - narrada detalhadamente na obra — se deu na noite do dia 20 para o dia 21 de janeiro, no quarto de seu dormitório na Universidade, em Rouen. A percepção da passagem como o marco de seu aborto pode ser relacionada a uma concepção do lugar como o símbolo da possibilidade do fim de seu calvário, após ter percorrido sozinha o caminho rumo a Paris, cidade ainda desconhecida para ela. Destarte, a passagem se configura na obra como metáfora da mudança, pois, apesar de apenas com a expulsão do feto se realizar de fato o aborto, a introdução da sonda parece ser compreendida como o momento de sua fundação identitária em que sente matar a mãe e nascer enquanto mulher adulta.

Não só a passagem Cardinet, mas o quarto de Mme P.-R. — a"fazedora de anjos" a quem paga para realizar o aborto através da introdução de uma sonda — são os elementos referenciais mais emblemáticos da narrativa, na medida em que constituem o lugar da experiência de iniciação. O quarto de Mme P.-R. local exato da iniciação, da vida e da morte - parece obcecar a autora-narradora: "Chego à imagem do quarto. Ela excede a análise. Só posso imergir-me nela. [...] Durante anos eu vi esse quarto e essas cortinas como as via da cama onde estava deitada" (p. 302) ${ }^{19}$. Sua opção por reconstituir esse cenário não será entretanto empreender uma descrição ao modo realista, mas trazer para a escrita a imagem do lugar a partir da evocação da composição de um quadro:

(Se eu tivesse de representar por um único quadro esse acontecimento de minha vida, eu pintaria uma pequena mesa colada à parede, coberta de fórmica, com uma bacia esmaltada onde flutua uma sonda vermelha. Ligeiramente à direita, uma escova de cabelos. Não creio que exista um Atelier de la faiseuse d'anges em nenhum museu do mundo.) (p. 304) ${ }^{20}$

O quarto é descrito como se fosse uma pintura inexistente, como se a representação pela imagem, ou por sua descrição, fosse a única capaz de traduzir sua visão sobre o local. O recurso a descrição de imagens é comum nos livros de Ernaux, nos quais introduz, pela escrita, diferentes fotos que também contam sua história. Como destaca Jovita Maria Gerheim Noronha (2014), em La place, a autora recorre frequentemente à ekphrasis, que consiste na substituição da reprodução impressa das fotografias por sua descrição. Segundo Véronique Montémont, no artigo em que analisa os usos do material documentário na autobiografia: "uma descrição in absentia é primeiramente uma re-criação pela escrita" (p. 44) ${ }^{21}$. Em L'événement, ainda que este recurso não esteja tão presente, o quarto é descrito a partir de um quadro que não está no texto ou fora dele, o que parece sugerir a impossibilidade da narrativa de restituir completamente o acontecimento, de modo que é através dessa "descrição in absentia" que se
[19] "Je suis parvenue à l'image de la chambre. Elle excède l'analyse. Je ne peux que m'immerger en elle. [...] Pendant des années, j'ai vu cette chambre et ces rideaux comme je les voyais depuis le lit où j'étais couchée." (ERNAUX, 2011, p. 302)

[20] "(Si j’avais à répresenter par un seul tableau cet événement de ma vie, je peindrais une petite table adossée à un mur, couverte de formica, avec une cuvette émaillée où flotte une sonde rouge. Légèrement sur la droite, une brosse à cheveux. Je ne crois pas qu'il existe un Atelier de la faiseuse d'anges dans aucun musée du monde.)" (ERNAUX, 2011, p. 304)

[21] "Une description in absentia est d'abord une re-création par l'écriture" (MONTÉMONT, Véronique. Vous et moi: usages autobiographiques du materiau documentaire. Littérature, v. 2, n 166, pp. 40-54, 2012). 
[22] (ERNAUX, Annie. La honte. In : Écrire la vie. Paris Quatro-Gallimard, 2011, p. 211-267).

[23] (ERNAUX, Annie. Une femme. In : Écrire la vie. Paris Quatro-Gallimard, 2011, p. 553-597).

[24] "une ennemie de classe" (ERNAUX, 2011, p. 579). torna possível re-criar a cena.

A noção de passagem não se limita à imagem sugerida pela passagem Cardinet como metáfora da iniciação da jovem, de sua entrada no mundo adulto, através da experiência do aborto, mas pode adquirir outras significações. Uma outra significação possível, mais abrangente, é a situação e o posicionamento da intelectual trânsfuga de classe, inclusive no que diz respeito a sua escolha de uma forma de escrita que se aproxime à do etnógrafo, em constante diálogo com a sociologia. Podemos citar o exemplo da presença da cidade em que cresceu nas suas obras. Annie Ernaux, apesar de ter nascido em Lillebone, muda-se para Yvetot aos cinco anos, onde encontra uma paisagem de ruínas devido aos bombardeios da Segunda Guerra Mundial. É nessa cidade que a autora passa sua infância e adolescência até ir para o liceu em Rouen. Sua relação com Yvetot está muito presente em duas narrativas autobiográficas da autora: La place e La honte $(1997)^{22}$.

Em La place, Yvetot aparece apenas como "Y"e sem uma descrição detalhada, de modo que seu lugar de formação permanece sem nome. A cidade, no entanto, compreende os dois lugares antagônicos frequentes em suas obras: o espaço familiar e o espaço da escola, já retratados em Les armoires vides (1974), sua primeira obra publicada. No espaço familiar, a narradora convive com o mundo de seus pais, que apesar de terem deixado a vida operária e se tornado proprietários de um café-épicerie, não passaram a fazer parte da classe dominante como a filha, integrando apenas outra categoria da classe dominada. Sobretudo em relação a seu pai, que teve de abandonar a escola para trabalhar, podemos observar como a aquisição de capital cultural e simbólico pela narradora a distanciou de seu meio de origem - em relação à mãe também afirma em Une Femme [Uma mulher] (1987) ${ }^{23}$ ter se tornado para ela "uma inimiga de classe" (p. 579) ${ }^{24}$.

Em La Honte [A vergonha], a autora-narradora relata uma cena que marcara sua infância: quando seu pai em um acesso de raiva quase matou a mãe. A "vergonha", além da associação direta ao ato violento do pai, pode ser relacionada, igualmente, à vergonha que sentia de seu meio familiar em comparação às famílias das outras meninas que frequentavam a mesma escola particular. Na narrativa, a autora, além de sua escola e a relação da mãe com o pai, descreve a cidade de "Y":

Ao redor do centro, irradiam ruas pavimentadas ou asfaltadas, contornadas por casas de dois andares de tijolos ou pedras e por calçadas, por propriedades isoladas atrás de grades, ocupadas pelos tabeliões, médicos, diretores e etc. Encontram-se também as escolas públicas e particulares, afastadas umas das outras. Não é mais o centro, mas sempre a cidade. Além dali, estendem-se os bairros cujos habitantes dizem que eles vão "à cidade" ou mesmo 
"a Y." quando vão ao centro. O limite entre o centro e os bairros é geograficamente incerto: o final das calçadas, o aumento do número de casas velhas (de madeira, com dois ou três cômodos no máximo, sem água corrente, os banheiros do lado de fora), de hortas, cada vez menos comércios, a não ser uma merceariacafé-carvoaria, surgimento dos conjuntos habitacionais. Mas é claro para todo mundo na prática: o centro é onde não se vai fazer compras de chinelo ou com uniforme de trabalho. $O$ valor dos bairros diminui à medida que se distancia do centro, que as grandes casas ficam mais raras e que os blocos de casas com um pátio comum se tornam mais numerosos. Os mais afastados, com caminhos de terra, de lama quando chove, e as fazendas atrás dos taludes, pertencem já ao campo. (p. 227) ${ }^{25}$

A cidade é descrita a partir de uma separação não só geográfica, mas social. Na narrativa de La honte, a autora situa as marcas de seu meio social de origem, a partir da divisão da cidade, traçando aquilo que compõe seu habitus, ou seja, o modo de perceber e de se comportar no mundo, em um papel de etnóloga de si mesma, como ela própria afirma.

A autora explica, em Retour à Yvetot, a respeito de La honte: "Perceba que não escrevo "Yvetot" inteiro, apenas $Y$, porque para mim é uma cidade mítica, a cidade de origem" (p.18) ${ }^{26}$. Diferentemente de La place, Yvetot, ainda que não nomeada, é descrita detalhadamente, nesta narrativa que aborda um acontecimento traumático que demanda o silêncio, por seu caráter propulsor da vergonha social. À vista disso, Violaine Houdart-Merot ${ }^{27}$ assinala que a descrição do lugar se torna importante para Ernaux apenas quando ela é capaz de revelar algo invisível, escondido ou tabu. Tal postulação pode ser associada também à forma como a autora-narradora de L'événement busca passar com certa precisão as informações sobre suas visitas à passagem Cardinet, outro lugar ligado ao tabu.

Como explicita em Le vrai lieu [O verdadeiro lugar] $(2014)^{28}$, Ernaux vive em Cergy desde 1977, lugar que também pode ser compreendido de modo metafórico. Nesta "cidade nova" dos arredores de Paris ${ }^{29}$, a autora escreveu todos os seus livros, com exceção dos dois primeiros. Sua casa em Cergy ao mesmo tempo é próxima o suficiente para dali se verem as luzes de Paris, mas está fora da capital, o que a autora associa a seu próprio lócus enunciativo: “Creio que isso corresponde bem ao que sinto em relação a Paris, talvez até mesmo em relação ao meu lugar no mundo. Em Paris, no fundo - pode parecer curioso dizer isso eu nunca entrarei..." (p. 14) ${ }^{30}$. A célebre capital francesa pode ser associada a um lugar "de direito" da classe dominante, ao qual aqueles vindos da periferia e do interior jamais pertenceriam. Ernaux, apesar de assumir o lugar de "trânsfuga", se mantém na passagem, ressaltando, através de sua escrita, como alguns discursos
[25] "Autour du centre rayonnent des rues pavées ou goudronées, bordées de maison à étages en brique ou pierre et de trottoirs, de propriétés isolées derrière des grilles, occupées par des notaires, médécins, directeurs, etc. S'y trouvent aussi les écoles publiques et privées, éloignées les unes des autres. Ce n'est plus le centre, mais toujours la ville. Audelà s'étendent les quartiers dont les habitants disent qu'ils vont 'en ville' ou même 'à Y.' quand ils se rendent dans le centre. La limite entre le centre et les quartiers est géographiquement incertaine: fin des trottoirs, davantage de vielles maisons (à colombage, de deux ou trois pièces au plus, sans eau courante, les cabinets au-dehors), de jardins de légumes, de moins en moins de commerces en dehors d'une épicerie-café-charbons, apparition des 'cités'. Mais claire pour tout le monde dans la pratique: le centre, c'est là où l'on ne va pas faire ses courses en chaussons ou en bleu travail. La valeur des quartiers diminue au fur et à mesure qu'on s'éloigne du centre, que les villas se raréfient et que les pâtés de maisons avec une cour commune deviennent plus nombreux. Les plus reculés, avec des chemins de terre, des fondrières quand il pleut et des fermes derrière des talus, appartiennent déjà à la campagne." (ERNAUX, 2011, p. 227).

[26] "Notez que je n'écris pas 'Yvetot' en entier, seulement $Y$, parce que pour moi, c'est une ville mythique, la ville d'origine."(ERNAUX, 2013, p. 18). 
[27] Em uma conferência, em 19 de abril de 2015, intitulada "Annie Ernaux: une écriture de lieux, d'Yvetot à Cergy" realizada pelo pesquisador Pierre Louis-Fort.

[28] ERNAUX, Annie. Le vrai lieu. Paris: Éditions Gallimard, 2014.

[29] No final dos anos 1960, devido à rápida aglomeração em Paris, decidiu-se equilibrar o excesso de urbanização através da criação de "villes nouvelles" [cidades novas] ao redor da capital.

[30] "Je crois que ça correspond bien à ce que je ressens vis-à-vis de Paris, peut-être même par rapport à ma place dans le monde. Paris au fond - ça peut paraître curieux de dire ça - je n'y entrerai jamais..." (ERNAUX, 2014, p. 14).

[31] “L'image qui me vient toujours pour l'écriture, c'est celle d'une immersion. De l'immersion dans une réalité qui n'est pas moi. Mais qui est passée par moi. Mon expérience est celle d'un passage et d'une séparation du monde social. Cette séparation existe dans la réalité, séparation des espaces, des systèmes éducatifs, ces enfants qui vont quitter l'école à 16 ans en sachant si peu de choses, et d'autres qui continuent jusqu'à 25. II y a une homologie entre la séparation du monde social et celle qui a traversé mon existence, une forme de coïncidence qui fait qu'écrire pour moi ce n'est pas m'intéresser à ma vie mais saisir les mécanismes de cette séparation."(ERNAUX, 2014, p. 65). são compreendidos como mais legítimos do que outros e se situando em uma posição próxima, porém ainda fora do mundo dos dominantes. Nesse sentido, sua casa em Cergy se apresenta como metáfora de seu lócus enunciativo, lugar de onde se podem ver as luzes de Paris, mas que se encontra à distância do espaço central da capital, sendo a escrita seu único lugar realmente:

A imagem que sempre me vem para a escrita é a de uma imersão. Da imersão em uma realidade que não sou eu. Mas que passou por mim. Minha experiência é a de uma passagem e de uma separação do mundo social. Essa separação existe na realidade, separação dos espaços, dos sistemas educativos, essas crianças que vão abandonar a escola aos 16 anos sabendo tão pouco, e outras que continuam até os 25. Há uma homologia entre a separação do mundo social e aquela que atravessou minha existência, uma forma de coincidência que faz com que escrever para mim não seja me interessar sobre a minha vida, mas compreender os mecanismos dessa separação. (p. 65, grifo nosso) $)^{31}$

O "verdadeiro lugar" para a autora, ao qual se refere o título do livro, é sua escrita, que ela concebe como uma forma de compensação de sua ascensão, afirmando pretender, através dessa ascensão, pensar e compreender os mecanismos de segregação social. A experiência da passagem, situada pela autora no centro de sua escrita, pode ser associada, então, à significação simbólica atribuída à passagem Cardinet como o lugar de uma separação, não só da mãe, mas também de seu meio social. Assim como a autora afirma que a Yvetot de seus livros é um lugar mítico por ser a cidade da origem, a passagem Cardinet também assume uma dimensão semelhante, relacionada à "prova iniciática" nela vivida, que pode ser pensada como o marco de sua ruptura com seu meio social. Dessa forma, os lugares físicos presentes nas obras de Ernaux parecem importar mais por sua dimensão simbólica do que por seu valor referencial. Na passagem Cardinet dá-se o "rito de passagem" da autora-narradora à idade adulta, ao mesmo tempo em que ela rompe com a fatalidade capaz de impedir sua ascensão à classe dominante, a gravidez fora do casamento. $\mathrm{O}$ aborto pode ser associado, dessa forma, a uma passagem que faz com que sua origem retorne.

\section{ABORTO CLANDESTINO: ENCONTROS ENTRE CLASSE E GÊNERO}

Em Les armoires vides, obra ficcional, ao abordar uma história de alienação social mesclada ao aborto, no presente da narrativa, Ernaux entrelaça as duas experiências. Denise Lesur, a narradora, fala sobre o conflito entre os mundos, 
da família e da escola, que vivenciara durante a infância. Tais espaços podem ser associados, respectivamente, aos valores das classes populares, presentes no convívio de casa e do café-épicerie, propriedade dos pais, e aos da escola burguesa. Na narrativa, segundo Nora C. Cottile-Foley ${ }^{32}$, o aborto é uma forma de expressão da alienação social da protagonista, que conta sua história enquanto o líquido amniótico vaza de seu corpo. A personagem-narradora relaciona sua experiência à inadequação de seu meio de origem. Ao entrar no mundo educado e burguês da escola privada, ela é confrontada a uma realidade antagônica à de sua família, e começa a associar o "mau gosto" a seu meio:

Os risos, a felicidade, e de repente tudo azedou feito leite velho, me vejo, me vejo e não pareço com as outras... Não quero acreditar nisso, por que não serei como elas, uma pedra dura no estômago, as lágrimas ardem. Não é mais como antes. Isso, a humilhação. Na escola, eu a conheci, a senti. Tem aquelas que passaram perto, que não senti, não prestava atenção. Logo tinha visto que não se parecia com a minha casa, que a professora não falava como meus pais, mas eu ficava natural, no início, eu misturava tudo. Não é um moinho, senhorita Lesur! Você não sabe, então que... Aprenda que... Você saberá que... No entanto, era a professora que estava errada, eu sentia. Sempre perto. Além disso quando ela dizia "seu papai, sua mamãe Ihe permitiriam entrar sem bater?" separando as palavras, eu tinha a impressão que ela falava de pessoas completamente desconhecidas, uma imagem decalcada que flutuava atrás de mim, a quem ela falava"(p. 136) ${ }^{33}$

Esses mundos são constantemente contrastados, desencadeando um sentimento de humilhação que aparece repetidas vezes. $O$ aborto é considerado por ela como uma culminação do "mau gosto" intrínseco a sua classe. Porém, apesar de não possuir o capital cultural incorporado através da herança familiar, pelo processo de aculturação ela consegue modificar a percepção que os outros têm de si, afastando-se de seu habitus popular:

De uma sala a outra, na escola particular, eram sempre as mesmas meninas. Elas aceitaram minhas notas boas e meu primeiro lugar. Era minha liberdade, meu calor, minha carapaça. Ser de novo a pequena rainha. A professora me perdoa tudo, os atrasos na aula, as conversas, as faltas de educação, por causa da nota dez em tudo, as lições sempre sabidas. (p. 144) ${ }^{34}$
[32] COTILLE-FOLEY, Nora C. "Abortion and Contamination of the Social Order in Annie Eranux's Les Armoires vides". The French Review, v.72, n.5, pp. 886-896, 1999.

[33] "Les rires, le bonheur, et tout à coup ça tourne comme du vieux lait, je me vois, je me vois et je ne ressemble pas aux autres... Je ne peux pas le croire, pourquoi je ne serais pas comme elles, une pierre dure dans l'estomac, les larmes piquent. Ce n'est plus comme avant. Ça l'humiliation. À l'école, je l'ai apprise, je l'ai sentie. II y en a qui sont sûrement passées à côté, que je ne sentais pas, je ne faisais pas attention. J'avais bien vu aussitôt que ça ne ressemblait pas à chez moi, que la maîtresse ne parlait pas comme mes parents, mais je restais naturelle, au début, je mélangeais tout. Ce n'est pas un moulin, mademoiselle Lesur ! Vous ne savez donc pas que... Apprenez que... Vous saurez que... C'est pourtant la maîtresse qui avait tort, je le sentais. Toujours à côté. D'ailleurs quand elle disait 'votre papa, votre maman vous permettent-ils d'entrer sans frapper ?' en détachant les mots, j'avais l'impression qu'elle parlait de gens tout à fait inconnus, un décalque qui flottait derrière moi, à qui elle parlait." (ERNAUX, 2011, p. 136)

[34] "D'une classe à l'autre, à l'école libre, c'estait toujours les mêmes filles. Elles ont admis mes bonnes notes et ma place de première. C'était ma liberté, ma chaleur, ma carapace. Redevenue la petite reine. La maîtresse me pardonne tout, les retards en classe, le bavardages, les fautes d'éducation, à cause des dix sur dix, des leçons toujours sues." (ERNAUX, 2011, p. 144). 
[35] "embody her origins while the outer surface of her body is vested with her new bourgeois identity" (COTTILE-FOLEY, 1999, p. 889)

[36] "shows how the bourgeoisie defines itself by defining a field of absolute Otherness" (COTTILE-FOLEY, 1999, p. 888)
[37] "This exclusionary matrix by which subjects are formed thus requires the simultaneous production of a domain of abject beings, those who are not yet "subjects," but who form the constitutive outside to the domain of the subject. The abject designates here precisely those "unlivable" and "uninhabitable" zones of social life which are nevertheless densely populated by those who do not enjoy the status of the subject, but whose living under the sign of the "unlivable" is required to circumscribe the domain of the subject." (BUTLER, Judith. Bodies That Matter. Nova lorque: Routledge, 1993, p. 3).
O conhecimento se torna, então, uma espécie de máscara que se constitui em uma nova identidade, a "carapaça" necessária para ser aceita nesse outro espaço. Contudo o aborto aparece como uma doença que internamente "incorpora suas origens ao passo que a superfície externa de seu corpo está revestida com a nova identidade burguesa" (p. 889) ${ }^{35}$, de modo que ele representaria aquilo que permaneceu dentro da carapaça.

São recorrentes na obra imagens que fazem alusão ao vômito, à urina, ao cuspe, no cenário da família, que podem ser associadas aos líquidos que fluem de seu corpo durante o aborto. Para a pesquisadora, a narrativa "mostra como a burguesia se define ao definir um campo de absoluta Outridade" (p. 888) ${ }^{36}$. Esse outro é o periférico, o marginal, associado às funções corporais que aparecem no texto em relação à protagonista e àqueles de seu convívio familiar e do caféépicerie de seus pais - que se localiza também em uma região periférica da cidade. Desse modo, é possível estabelecer conexões entre a gravidez, o aborto e a classe dominada. Judith Butler, em Bodies That Matter (1993), propõe um pensamento baseado na existência de uma matriz que pelo mesmo processo delimita os sujeitos, produz os "abjetos", aqueles que são, a um só tempo, excluídos e necessários:

Essa matriz excludente pela qual os sujeitos são formados requer, assim, a produção simultânea de um domínio de seres abjetos, aqueles que ainda não são "sujeitos", mas que formam o fora constitutivo do domínio do sujeito. $O$ abjeto designa aqui precisamente aquelas zonas "inviviveis"e "inabitáveis" da vida social que são, ainda assim, densamente povoadas por aqueles que não gozam do status de sujeito, mas cujas vidas sob o signo do "invivível" são necessárias para circunscrever o domínio do sujeito. (BUTLER, 1993, p. 3) ${ }^{37}$

A abjeção, no pensamento butleriano, diz respeito aos corpos e às vidas que estão fora da norma, mas que não deixam de ser necessários para que esta possa existir. Isto posto, os abjetos podem ser pensados como os marginalizados da inteligibilidade cultural, que não se conformam à figura distinta da norma do sujeito, produzida a partir da expulsão daquilo que se relaciona à animalidade, ao monstruoso, ao não-humano. Em Les armoires vides, a abjeção está na presença do corpo e de suas funções fisiológicas, associado ao "mau gosto", à inadequação da origem social da protagonista, que ainda carrega em si, em seu ventre, seu estigma. Também em L'événement, a gravidez indesejada é relacionada ao destino de sua classe de origem, de modo que o sexo aparece como aquilo que não permitiu que escapasse do "fracasso social": 
Eu estabelecia de forma confusa uma ligação entre minha classe social de origem e o que me acontecia. Primeira a fazer um curso superior numa família de origem operária e de pequenos comerciantes, eu escapara da fábrica e do balcão. Mas nem o "bac"38, nem a graduação em letras puderam mudar a fatalidade da transmissão de uma pobreza cuja jovem grávida era, da mesma forma que o alcoólatra, o emblema. O sexo me fez voltar à minha origem esquecida e o que crescia em mim era, de certa maneira, o fracasso social. (p. 280) $)^{39}$

A narradora fala da gravidez e do alcoolismo como as fatalidades decorrentes de seu lugar social, quando não a prostituição ou a profissão de operária. Também em outros momentos ela se identifica com os marginalizados, os excluídos da matriz, segundo a definição de Butler, aqueles que ocupam as zonas "inabitáveis", porém "densamente povoadas" dos que não são reconhecidos como sujeitos: "em relação a eles [os outros estudantes], nesse mundo de referência, tornarame internamente uma delinquente" (p. 289) ${ }^{40}$. Quando o sexo e a gravidez a trazem de volta a sua "origem esquecida", a autora-narradora estava em pleno processo de mobilidade social, por já ter seu diploma em letras, o que podemos compreender como uma forma de se tornar sujeito e ocupar o centro da matriz, afastando-se do domínio dos seres supostamente menos racionais, como propõe Butler, incumbidos de performar a corporalidade. Porém, de certa maneira, operase um movimento de retorno à marginalidade, evidenciada por ela ao se ver separada dos outros, em um processo de "exclusão do mundo normal" (p. 289) ${ }^{41}$ como uma "delinquente".

Podemos, igualmente, observar essa associação com os marginalizados, quando a autora faz uma analogia entre a visão sobre a prática do aborto nos anos 1960 à travessia dos refugiados no final dos anos 1990:

No momento em que escrevo, os refugiados kosovares, em Calais, tentam entrar clandestinamente na Inglaterra. Os contrabandistas de pessoas exigem somas enormes e às vezes desaparecem antes da travessia. Mas nada detém os kosovares, nem tampouco todos os migrantes dos países pobres: eles não têm outra salvação. Perseguem-se os contrabandistas, deplora-se a existência deles como há trinta anos aquela das mulheres que praticavam abortos. (p. 305) ${ }^{42}$

Os refugiados em período de conflito são aqueles que, como destaca Judith Butler em Quadros de Guerra (2015), estão vivos mas não são considerados "vidas",
[38] Abreviação de baccalauréat, um diploma do sistema de ensino francês.

[39] "J'établissais confusément un lien entre ma classe sociale d'origine et ce qui m'arrivait. Première à faire des études supérieures dans une famille d'ouvriers et de petits commerçants, j'avais échappé à l'usine et au comptoir. Mais ni le bac ni la licence en lettres n'avaient réussi à détourner la fatalité de la transmission d'une pauvreté dont la fille enceinte était, au même titre que l'alcoolique, l'emblème. J'étais ratrapée par le cul et ce qui poussait en moi c'était, d'une certaine manière, l'échec social." (ERNAUX, 2011, p. 280).

[40] "par rapport à eux, à ce monde de référence, j'étais devenue intérieurement une délinquante" (ERNAUX, 2011, p. 289).

[41] "exclusion du monde normal” (ERNAUX, 2011, p. 289).

[42] “Au moment où j'écris, des réfugié kosovars, à Calais, tentent de passer clandestinement en Anglaterre. Les passeurs exigent des sommes énormes et parfois disparaissent avant la traversée. Mais rien n'arrête les Kosovars, non plus que tous les migrants des pays pauvres : ils n'ont pas d'autre voie de salut. On pourchasse les passeurs, on déplore leurs existence comme il y a trente celle des avorteuses. " (ERNAUX, 2011, p. 305). 
[43] "Et cette inégalité, elle était sensible pour moi dans le souvenir de la terrible difficulté que, sans argent et sans relations, j'avais eue pour trouver un moyen d'avorter, alors que certaines filles, riches, avaient, au même moment, pu sans problème aller en Suisse où c'était autorisé.".

[44] “j'ai cru qu'il était capable de me laisser mourir si je ne le jurais pas" (ERNAUX, 2011, p. 310). estando em meio a uma violência legalizada. São indivíduos marginalizados e humilhados por suas existências não estarem completamente dentro do domínio dos seres reconhecidos enquanto sujeitos. Assim também são vistos aqueles que os ajudam a atravessar a fronteira, operando uma espécie de contaminação desse espaço aos quais os refugiados não pertenceriam "naturalmente" por sua posição periférica. Como a ação dos contrabandistas é relacionada àquela das aborteiras, é possível associar, igualmente, as mulheres que abortam aos migrantes à procura de uma solução para a situação ameaçadora na qual se encontram. Através dessa analogia, a autora-narradora chama a atenção para a situação precária à qual as mulheres, principalmente as das classes dominadas, se submetiam em um período de interdição do aborto. Tal referência pode ser vista como uma forma de assinalar o problema social em torno da proibição do aborto, pois a lei também é responsável por gerar a marginalidade, os supostos criminosos cuja existência é reconhecida sob o signo da abjeção.

Na França dos anos 1960, apesar da proibição, as mulheres de famílias abastadas podiam ir a outro país realizar o procedimento de forma segura, ao passo que as mulheres da classe dominada não tinham essa opção, como ocorre com a autora-narradora de L'événement. Em Le vrai lieu, Ernaux critica o feminismo dos anos 1970, que não diferenciava as mulheres burguesas das do meio popular, como se vivessem sob as mesmas condições e sofressem as mesmas violências. Para a autora, a clivagem entre elas está no encontro da dominação masculina com a social, de modo que seu próprio aborto seria um exemplo dessa diferença, então negligenciada pelo feminismo:

E essa desigualdade era sensível para mim na lembrança da terrível dificuldade que, sem dinheiro e sem relações, tivera para encontrar um modo de abortar, enquanto algumas moças, ricas, no mesmo momento, puderam sem problemas ir à Suiça onde era autorizado. (p. 58) $)^{43}$

Na representação do corpo médico na obra podemos perceber também uma manifestação da violência simbólica que, segundo Bourdieu, é uma forma de violência tácita que faz com que as relações de dominação sejam incorporadas enquanto naturais. A exemplo da postura do médico que a atende no dormitório da Universidade - logo após a expulsão do feto — que a faz jurar, antes mesmo de tomar as medidas necessárias, que não fará aquilo novamente, sobre o que ela comenta "acreditei que ele era capaz de me deixar morrer se eu não jurasse" (p. 310$)^{44}$.

Também figura em sua narrativa uma ênfase na forma hostil como é tratada uma vez no hospital, no momento da curetagem, quando o cirurgião se dirige a ela aos gritos, o que a autora explica em seguida compreender como um símbolo 
da hierarquização da sociedade:

("Eu não sou o encanador!" Essa frase, como todas aquelas que marcam esse acontecimento, frases muito ordinárias, proferidas por pessoas que as diziam sem refletir, ainda repercute em mim. Nem a repetição, nem um comentário sociopolítico podem atenuar a violência: eu não "o esperava". De modo fugaz, creio ver um homem de branco, com as luvas de borracha, que me enche de pancada gritando "eu não sou o encanador!". E essa frase, inspirada talvez por um sketch de Fernand Raynaud que fazia a França inteira rir, continua a hierarquizar o mundo em mim, a separar, a golpes de cassetete, os médicos dos operários e das mulheres que abortam, os dominantes dos dominados.) (p. 311) ${ }^{45}$

A frase do residente manifesta, em suas poucas palavras, o desprezo em relação à classe social e ao gênero. Ele compara seu trabalho de parar o sangramento na jovem à atividade de um encanador que deve consertar um cano, o que é também uma forma de reificação do corpo daquela mulher. Ao longo da narrativa, podemos observar a repetição das frases ouvidas pela autora-narradora durante o período, o que permite que o texto exponha os detalhes e sensações produzidas pela experiência. $O$ recurso à citação na obra de Ernaux, para Havercroft (2015), pode ser considerado como um dos exemplos do agenciamento ${ }^{46}$ da autora, que ao repetir em seus livros as frases e situações ouvidas ou lidas, evidencia os costumes e preconceitos de uma época, ao mesmo tempo em que performa uma crítica social.

Ao citar a frase dita pela enfermeira de plantão do hospital - que a visita no meio da noite para contar a reação do residente ao descobrir que se tratava de uma estudante e não de "uma operária têxtil ou de uma vendedora do Monoprix $\left.{ }^{47 " ~(p . ~ 312) ~}\right)^{48}$ - a autora destaca, igualmente, a forma de pensar e agir de um grupo social em uma dada época, enfatizando a naturalização da violência simbólica:

Todas as luzes estavam apagadas depois de bastante tempo. $A$ enfermeira da noite, uma mulher de cabelos grisalhos, voltou ao meu quarto, se aproximou silenciosamente até a cabeceira da minha cama. Na penumbra da luz noturna, eu a via indulgente. Ela cochichou num tom de bronca: "Na noite passada, por que você não disse ao doutor que você era como ele?" Depois de alguns segundos de hesitação, eu compreendi que ela queria dizer: do mundo dele. Ele descobrira que eu era estudante apenas depois da curetagem, sem dúvidas por minha carteirinha da
[45] "('Je ne suis pas les pompier!' Cette phrase, comme toutes celles qui jalonnent cet événement, des phrases très ordinaires, proférées par des gens qui les disent sans réfléchir, déflagre toujours en moi. Ni la répétition ni un commentaire sociopolitique ne peuvent en atténuer la violence : je ne 'l'attendais' pas. Fugitivement, je crois voir un homme en blanc, avec des gants de caoutchouc, qui me roue de coups en hurlant, 'je ne suis pas le pompier !'. Et cette phrase, que lui avait peut-être inspirée un sketch de Fernand Raynaud qui faisait alors rire toute la France, continue de hiérarchiser le monde en moi, de séparer, comme à coups de trique, les médecins des ouvriers et de femmes qui avortent, les dominants des dominés.)" (ERNAUX, 2011, p. 311).

[46] O conceito compreendido como um termo que "se refere a ações individuais ou em grupo consideradas significativas dentro de um ambiente social ou institucional específico" (MANN, 1994, p. 14) e, segundo Sara Salih (2015), enquanto a possibilidade de subverter a lei para que ela volte contra si mesma com intenções políticas e radicais, representando a capacidade do sujeito de agir na construção da própria subjetividade apesar dos discursos da norma que agem em sua constituição.

[47] Uma grande rede francesa de supermercados.

[48] "une ouvrière du textile ou une vendeuse de Monoprix" (ERNAUX, 2011, p. 312). 
[49] Mnef é a abreviação de Mutuelle nacionale des étudiants de France [Associação nacional dos estudantes da França], um seguro social para os estudantes.

[50] "Toutes les lumières étaient éteintes depuis assez longtemps. La garde de nuit, une femme à cheveux gris, est revenue dans ma chambre, s'est approchée silencieusement jusqu'à la tête de mon lit. Dans la pénombre de la veilleuse, je la voyais bienveillante. Elle m'a chuchoté d'une voix grondeuse : « La nuit dernière, pourquoi vous n'avez pas dit au docteur que vous étiez comme lui ? » Après quelques secondes d'hésitation, j'ai compris qu'elle voulait dire : de son monde à lui. Il avait appris que j'étais étudiante seulement après le curetage, sans doute par ma carte de la Mnef. Elle mimait l'étonnement et la colère de l'interne, indignée elle-même de mon attitude. J'ai dû penser qu'elle avait raison et que c'était ma faute s'il était conduit violemment : il se savait pas à qui il avait affaire." (ERNAUX, 2011, p. 313).

[51] "fente de clarté" (ERNAUX, 2011, p. 303).

\begin{abstract}
Mnef. ${ }^{49}$ Ela imitava o espanto e a cólera do residente, "mas enfim, por que ela não me disse, por que!', como se estivesse ela própria indignada por minha atitude. Eu devo ter pensado que ela tinha razão e que era minha culpa se ele se comportara violentamente: ele não sabia com quem estava falando. (p. 313) ${ }^{50}$
\end{abstract}

Na pergunta da enfermeira, podemos observar hierarquização entre os estudantes e os operários, na qual ela faria parte do segundo grupo, o do mundo dominado, por estar em uma posição considerada inferior. A indignação expressada pelo residente se deve a ter descoberto que a narradora não pertencia ao mundo dos operários, o que o faz lamentar a forma como a tratou. Porém, ela se situaria, na verdade, nos dois mundos, àquele dessa mulher que tem um emprego que não demanda um grande acúmulo de capital cultural e ao do estudante de medicina que reproduz os preconceitos sociais naturalizados. A internalização dessa dominação é assumida pela própria narradora que afirma ter pensado que poderia ser sua culpa, por ela não ter avisado quem era. De certo modo, o status de estudante aparece como um lugar de humanização e legitimação de sua vida, que demanda um tratamento melhor do que o que seria dado a uma operária. À vista disso, observamos que o texto é capaz de evidenciar como o acúmulo de capital cultural é uma forma de obter legitimidade e, até mesmo, o direito a ser visto como um ser humano. Esse processo é aceito pela própria enfermeira, cuja personagem pode ser pensada como a representação dos indivíduos da classe dominada que incorporam a violência da classe dominante.

\section{CONSIDERAÇÕES FINAIS}

A narrativa de Ernaux destaca como se interligam as violências invisíveis e naturalizadas que não são apenas fruto da condenação do aborto, mas da interação dos diferentes mecanismos de controle e dominação. Dessa forma, ainda que a experiência narrada possua elementos únicos só vividos por ela, ao levantar essa discussão, a autora inscreve sua experiência particular na história, assinalando as injustiças e preconceitos de um determinado tempo e expondo aquilo que, pelo incômodo gerado, permanecia velado. Por sua condição de trânsfuga, a autora se situa em um lugar de passagem entre as gerações, entre esses dois mundos, produzindo uma obra que narra como se dá essa passagem e ruptura vividas pelo seu próprio corpo. Como a gravidez na narrativa é sempre associada a um problema, a uma doença e a uma marca de sua classe, a introdução da sonda em seu ventre se configura, a um só tempo, como experiência brutal e solução para o seu estado. A única "fenda de luz" (p. $303)^{51}$ que vê no fundo da passagem Cardinet, ao sair do quarto de Mme P.-R. 
pode ser considerada como metáfora de um caminho que se abre novamente. $O$ aborto permite que ela não tenha o mesmo destino de outras jovens de seu meio social de origem e possa continuar sua ascensão social, embora isso não apague a violência sofrida. A experiência pode ser, dessa forma, caracterizada como um segundo nascimento, por ser sua iniciação na idade adulta, mas, igualmente, por representar o agenciamento do sujeito que rompe com a prisão social e de gênero. Nessa perspectiva, Mme P. -R. simbolizaria na narrativa tanto aquela que lhe oferece outro nascimento, quanto sua origem social: "ela é para mim uma figura do meio popular, do qual eu estava, então, me afastando" (p. 303) ${ }^{52}$.

Em uma entrevista a Pierre-Louis Fort (2003), Ernaux alega julgar a origem social mais determinante em sua escrita do que a individuação sexual, pois considera que não se escreve da mesma maneira quando se é oriundo das classes populares. Porém, não nos parece que a problemática do gênero esteja de fato ausente de seus textos, mas antes se conjuga à questão da classe social, como observamos na obra em questão. Em L'événement, Ernaux traz para sua escrita algumas das dimensões do encontro dessas duas dominações, evidenciando como ser de uma origem popular e ter um corpo reconhecido como feminino atuaram diretamente em sua trajetória. Resta dizer que, apesar desses temas serem contumazes em seus textos, Ernaux não faz de sua literatura um mero manifesto político, mas, ao contrário, mobiliza diversos recursos em sua escrita para restituir sua experiência e criar efeitos que excedem o da forma pura da arte afastada do mundo, engendrando discussões literárias, mas também históricas, políticas, feministas e sociológicas.
[52] "elle est pour moi une figure du milieu populaire, dont j'étais alors en train de m'éloigner"'(ERNAUX, 2011, p. 303). 


\section{REFERÊNCIAS BIBLIOGRÁFICAS}

BOURDIEU, Pierre; PASSERON, Jean-Claude. A reprodução : elementos para uma teoria do sistema de ensino.. Petrópolis: Vozes, 2008.

A Distinção. Porto Alegre: Zouk, 2011.

BUTLER, Judith. Bodies That Matter. Nova lorque: Routledge, 1993 Quadros de guerra: quando a vida é passível de luto? Rido de Janeiro: Civilização Brasileira, 2015.

COTILLE-FOLEY, Nora C. "and Contaminatioon of the Social Order in Annie Eranux's Les Armoires vides". The French Review, v.72, n.5, pp. 886-896, apr. 1999. (American Association of Teachers of French).

ERNAUX, Annie. Écrire la vie. Paris: Gallimard, 2011..

Le vrai lieu. Paris: Éditions Gallimard, 2014.

Retour à Yvetot. Paris : Editions du Mauconduit, 2013.

"Bourdieu: Le chagrin". Le Monde, 05/02/2002. Disponível em: htp://www.homme-moderne.org/societe/socio/bourdieu/mort/aernau.html. Acesso: 10 mai 2016.

Entrevista concedida a Pierre-Louis Fort. The French Review, v.76, n.5, p. 984-994, apr. 2003. (American Association of Teachers of French).

HAVERCROFT, Barbara. "Lorsque le sujet devient agent: écriture et engagement chez Annie Ernaux". In: FORT, Pierre-Louis e HOUDART-MEROT, Violaine (org.). Annie Ernaux: Un engagement d'écriture. Paris : Presses Sorbone Nouvelle, 2015, p. 81-86.

HOUDART-MEROT, Violaine. "Altérité et engagement: 'soi-même comme un autre'". In: FORT, Pierre-Louis e HOUDART-MEROT, Violaine (org.). Annie Ernaux: Un engagement d'écriture. Paris : Presses Sorbonne Nouvelle, 2015, p. 91-99.

MANN, Patrícia S. Micro-politics: agency in a postfeminist era. Minnesota: University of Minnesota Press, 1994 
MONTÉMONT, Véronique. Vous et moi: usages autobiographiques du materiau documentaire. Littérature, v. 2, n 166, pp. 40-54, 2012.

NORONHA, Jovita Maria Gerheim. "Interfaces entre biografia e autobiografia na obra de Annie Ernaux”. In: DA ROCHA, Alberto Ferreira Jr. (org). Narrativas (auto)biográficas: literatura, discurso e teatro. São João Del Rei: UFSJ, 2014.

SALIH, Sara. Judith Butler e a Teoria Queer. Belo Horizonte: Autêntica editora, 2015.

THUMEREL, Fabrice. "Passage(s)" Ernaux. In: FORT, Pierre-Louis e HOUDARTMEROT, Violaine (org.). Annie Ernaux: Un engagement d'écriture. Paris : Presses Sorbone Nouvelle, 2015, p. 111-121. 